\title{
Distribution of silver in rats following 28 days of repeated oral exposure to silver nanoparticles or silver acetate
}

Katrin Loeschner ${ }^{1 *}$, Niels Hadrup ${ }^{2}$, Klaus Qvortrup ${ }^{3}$, Agnete Larsen $^{4}$, Xueyun Gao 5 , Ulla Vogel ${ }^{2,6}$, Alicja Mortensen ${ }^{2}$, Henrik Rye Lam ${ }^{2,7}$ and Erik H Larsen ${ }^{1 *}$

\begin{abstract}
Background: The study investigated the distribution of silver after 28 days repeated oral administration of silver nanoparticles (AgNPs) and silver acetate (AgAc) to rats. Oral administration is a relevant route of exposure because of the use of silver nanoparticles in products related to food and food contact materials.

Results: AgNPs were synthesized with a size distribution of $14 \pm 4 \mathrm{~nm}$ in diameter (90\% of the nanoparticle volume) and stabilized in aqueous suspension by the polymer polyvinylpyrrolidone (PVP). The AgNPs remained stable throughout the duration of the 28-day oral toxicity study in rats. The organ distribution pattern of silver following administration of AgNPs and AgAc was similar. However the absolute silver concentrations in tissues were lower following oral exposure to AgNPs. This was in agreement with an indication of a higher fecal excretion following administration of AgNPs. Besides the intestinal system, the largest silver concentrations were detected in the liver and kidneys. Silver was also found in the lungs and brain. Autometallographic (AMG) staining revealed a similar cellular localization of silver in ileum, liver, and kidney tissue in rats exposed to AgNPs or AgAc.

Using transmission electron microscopy (TEM), nanosized granules were detected in the ileum of animals exposed to AgNPs or AgAc and were mainly located in the basal lamina of the ileal epithelium and in lysosomes of macrophages within the lamina propria. Using energy dispersive $x$-ray spectroscopy it was shown that the granules in lysosomes consisted of silver, selenium, and sulfur for both AgNP and AgAc exposed rats. The diameter of the deposited granules was in the same size range as that of the administered AgNPs. No silver granules were detected by TEM in the liver.

Conclusions: The results of the present study demonstrate that the organ distribution of silver was similar when AgNPs or AgAc were administered orally to rats. The presence of silver granules containing selenium and sulfur in the intestinal wall of rats exposed to either of the silver forms suggests a common mechanism of their formation. Additional studies however, are needed to gain further insight into the underlying mechanisms of the granule formation, and to clarify whether AgNPs dissolve in the gastrointestinal system and/or become absorbed and translocate as intact nanoparticles to organs and tissues.
\end{abstract}

\section{Background}

Silver nanoparticles (AgNPs) are presently one of the most frequently used nanomaterials in consumer products [1] because of their proposed antimicrobial properties [2]. Silver in the form of $\mathrm{Ag}^{+}$ions has toxic effects on many pathogens, including bacteria, viruses, and

\footnotetext{
* Correspondence: kals@food.dtu.dk; ehlar@food.dtu.dk

'Division of Food Chemistry, National Food Institute, Technical University of Denmark, Søborg, Denmark

Full list of author information is available at the end of the article
}

fungi [3]. Because of its relatively low toxicity in humans, silver has been used in various medical applications [4]. The antibacterial activity of AgNPs also depends on the $\mathrm{Ag}^{+}$ion [3], which is readily formed on the nanoparticle surface due to reaction with oxygen. The antibacterial activity of AgNPs increases with decreasing particle size which has been associated with the increasing surface area-to-mass ratio [3].

In general, application of nanoparticles in products related to food and beverages is still rare [5]. AgNPs

\section{Biomed Central}


however, can already be found in a number of commercial products including food packing materials and kitchen appliances, and is even sold as an alternative "health supplement" [5,6]. Furthermore, silver nanoparticles are considered as a potential additive to animal feed to replace antibiotics $[7,8]$. Therefore, oral intake of silver nanoparticles is a relevant route of exposure for the consumer.

The toxicology of silver and its compounds has been studied for decades. Animal studies dealing with oral exposure to silver are nevertheless scarce. A summary of the available data has been given in the "Toxicological Profile for Silver" from the Agency for Toxic Substances and Disease Registry of the U.S. Public Health Service [9]. Although the toxicology of silver and its compounds has been studied, several knowledge gaps exist concerning the risk caused by silver in the form of nanoparticles, both to humans and to the environment [10]. It is for example not known to what extent intact AgNPs themselves enter the body or whether only silver ions originating from the nanoparticles are absorbed.

It is generally known that nanoparticles can be taken up by the intestinal system not only via M-cells in the Peyer's patches and the isolated follicles of the intestinal-associated lymphoid tissue, but also via enterocytes [11]. The degree of absorption is mainly governed by nanoparticle size, surface charge, hydrophobicity, and the presence or absence of surface ligands. It is generally agreed that absorption increases with decreasing particle diameter for sizes below $1 \mu \mathrm{m}$ [12]. Thus, aggregation of nanoparticles in the lumen of the gastro-intestinal tract can lead to decreased absorption.

In a 28-day repeated oral dose toxicity study, AgNPs of $60 \mathrm{~nm}$ in diameter and stabilized by $0.5 \%$ aqueous carboxymethylcellulose, were administered to rats [13]. A dosedependent increase of the silver concentration in the rat organs was observed with the highest concentrations in stomach, kidney and liver. However, it was not investigated whether the silver reached the tissues and organs as nanoparticles. Animal studies using other exposure routes revealed that intact AgNPs indeed could translocate to and deposit in a variety of organs of experimental animals. Following subcutaneous injection of 50-100 nm diameter AgNPs, discrete nanoparticles were found in kidney, liver, spleen, and lung tissue, as well as in vascular endothelial cells of the blood-brain barrier [14]. Intraperitoneally injected bovine serum albumin (BSA)-coated AgNPs of $2 \mathrm{~nm}$ in diameter were detected as larger aggregates in liver, kidney, and heart tissue, which was attributed to coalescence or aggregation events taking place in the blood serum or in the tissue [15].

The aim of the present study was to investigate the organ distribution and cellular localization of silver in rats following 28 days repeated oral exposure of either
AgNPs or silver acetate (AgAc). AgNPs were sterically stabilized with a polymer to assure the availability of well-characterized and stable nanoparticles throughout the duration of the animal experiment. AgAc was chosen for comparison because it is a soluble salt containing a biocompatible counter ion. Transmission electron microscopy (TEM) was applied to investigate whether intact AgNPs entered the intestinal wall of rats.

\section{Methods}

Unless stated otherwise, results based on repeated measurements are given as mean \pm 1 s.d. The number of repetitions $\mathrm{N}$ is stated in parentheses.

\section{Synthesis of the AgNPs}

AgNPs were produced by reducing silver nitrate with hydrazine in the presence of polyvinylpyrrolidone (PVP) [16]. An amount of $300 \mathrm{mg}$ of PVP powder (PVP-K30, BASF Ludwigshafen, Germany) was dissolved in $8 \mathrm{ml}$ of an aqueous $25 \mathrm{mM}$ silver nitrate solution $\left(\mathrm{AgNO}_{3}\right.$, A.R Beijing Chemical Factory, China). The mixture was diluted with $14 \mathrm{ml}$ deionized water. After $5 \mathrm{~min}$ at room temperature $4 \mathrm{ml}$ of $70 \mathrm{mM}$ hydrazine $\left(\mathrm{N}_{2} \mathrm{H}_{4} \cdot \mathrm{H}_{2} \mathrm{O}\right.$, A.R Beijing Zhonglian Reagent Fine Chemicals Co., Ltd., China) was added dropwise. Hydrazine was added in stoichiometric excess to achieve complete reduction of the silver salt. All steps were performed under continuous stirring. The final suspension was purified by centrifugation at 4,000 rpm $(1,467 \times g)$ for $10 \mathrm{~min}$ and by dialysis for $24 \mathrm{~h}$ against deionized water using a $14 \mathrm{kDa}$ membrane. The nanoparticle suspension was prepared in several batches which were later combined. Each batch was controlled by dynamic light scattering to ensure a similar size distribution of the AgNPs in each batch. An average nominal silver concentration of $450 \mu \mathrm{g} / \mathrm{ml}$ was estimated after production of the AgNPs and was based on measurements by inductively coupled plasma optical emission spectrometry.

\section{Characterization of the nanoparticle suspension}

The silver concentration of the AgNP suspensions was determined by using a quadrupole-based inductively coupled plasma mass spectrometer (ICP-MS 7500ce, Agilent Technologies, Japan). Before measurement, the suspensions were digested in $1 \mathrm{ml}$ concentrated nitric acid (PlasmaPure, SCP Science, Quebec, Canada) in a microwave oven (Multiwave, Anton Paar, Graz, Austria) at elevated temperature and pressure $\left(\sim 250^{\circ} \mathrm{C}, \sim 70\right.$ bar $)$. From three different bottles, five to six subsamples of $40 \mu \mathrm{l}$ were transferred to high pressure quartz vessels. After digestion the samples were diluted 500-times with deionized water. The concentration of Ag was quantified against an external calibration curve (Ag stock solution $1,000 \mu \mathrm{g} / \mathrm{ml}$ obtained from SCP Science, Quebec, Canada) with 
internal standardization (rhodium $(\mathrm{Rh})$ stock solution $1000 \mu \mathrm{g} / \mathrm{ml}$, SCP Science, Quebec, Canada). Prior to analysis the samples were further diluted (dilution factor 25), resulting in a nitric acid concentration of approximately $2 \% \mathrm{v} / \mathrm{v}$.

The silver isotope ${ }^{107} \mathrm{Ag}$ was chosen for the ICP-MS measurements because a slightly lower detection limit was obtained for this isotope. The limit of detection for the AgNP suspensions, which was estimated at $0.7 \mu \mathrm{g}$ $\mathrm{Ag} / \mathrm{ml}$, was based on three times the standard deviation from repeated measurements of blank solutions.

To determine the amount of silver in the suspensions that was not present as nanoparticles, filtrates of three subsamples were prepared by centrifugation through a micro centrifuge cellulose acetate filter with a molecular weight cut-off of $12 \mathrm{kDa}$ (VectaSpin Micro Centrifuge Filter, Whatman, England). A volume of $500 \mu \mathrm{l}$ of 10-times diluted suspension was centrifuged at $11,000 \mathrm{rpm}(8,117 \times$ $g$ ) for $30 \mathrm{~min}$ in a micro centrifuge (Eppendorf MiniSpin, Eppendorf AG, Hamburg, Germany). Because the AgNPs and the polymer could clog the membrane before all unbound silver had passed the filter, the residue in the filter cartridge was re-suspended twice in $500 \mu$ l of deionized water and filtered again. In order to investigate whether any silver gradually dissolved from the AgNPs over time, silver concentrations were determined in the filtrates at 3 and 16 weeks before and 5 months after the animal study.

Before analysis of the silver concentration by ICP-MS the filtrates were diluted 100-times with $2 \% \mathrm{v} / \mathrm{v}$ nitric acid and $\mathrm{Rh}$ was added as internal standard $(10 \mathrm{ng} / \mathrm{ml})$. The limit of detection for silver in the filtrates was $0.002 \mu \mathrm{g} / \mathrm{ml}$. To assure the quality of the previous results a Sorvall Discovery 90SE ultracentrifuge (Kendro Laboratory Products, Asheville, NC, USA) with an AH629 swinging bucket rotor was used as an alternative method for separation of the nanoparticles from the original AgNP suspension. A 10-times diluted suspension was transferred to a $17 \mathrm{ml}$ thin walled polyallomer tube and centrifugated at 29,000 rpm $(135,293 \times g)$ for $19 \mathrm{~h}$ at $20^{\circ} \mathrm{C} ; 500 \mu \mathrm{l}$ of supernatant were taken from the surface of the liquid. According to centrifugation theory the maximum particle diameter in the supernatant was below $1 \mathrm{~nm}$ [17]. The supernatant was analyzed by ICPMS using dissolution in acid as before.

The particle size and shape were observed by TEM using a Philips CM100 instrument (FEI, Eindhoven, The Netherlands) operated at $80 \mathrm{kV}$ accelerating voltage. The prepared silver suspensions were diluted 10-times with deionized water. A drop of the suspension was applied to a Formvar-coated copper grid.

Dynamic light scattering (DLS) and laser Doppler velocimetry for characterization of hydrodynamic size and zeta potential of the nanoparticles in solution were performed using a Zetasizer Nano-ZS instrument (Malvern
Instruments, UK). Before measurements the samples were diluted 10-times with deionized water. For DLS $250 \mu \mathrm{l}$ of suspension were transferred to a disposable low volume cuvette (Malvern, UK). After equilibration to a temperature of $25^{\circ} \mathrm{C}$ for $2 \mathrm{~min}$, five measurements were performed using 12 runs of $10 \mathrm{~s}$ each. The laser power (attenuator index) and the measurement position within the cuvette were determined automatically by the instrument. For the calculation of the nanoparticle volume size distribution the viscosity of water was used. The influence of PVP on the viscosity was neglected because the PVP concentration in the 10-times diluted suspensions was only $0.1 \% \mathrm{w} / \mathrm{v}$. The optical parameters for silver, namely index of refraction $\mathrm{n}=0.1$ and index of absorption $\mathrm{k}=4.28$ at $633 \mathrm{~nm}$ laser wavelength were applied according to Johnson and Christy [18]. The stability of the nanoparticles in suspension was monitored regularly by measuring the size distribution within 20 weeks after arrival of the suspensions until the beginning of as well as during the last week of the animal study.

For determination of the zeta potential, $800 \mu \mathrm{l}$ of suspension was transferred to a clear disposable zeta cell (Malvern, UK). After equilibration to a temperature of $25^{\circ} \mathrm{C}$ for $2 \mathrm{~min}$, five measurements were performed where the number of runs (10 to 100) was determined automatically by the instrument. The Smoluchowski approximation was used for calculation of the zeta potential.

\section{Animal study}

Four week old female Wistar Hannover Galas rats with specific pathogen-free health status were purchased from M\&B Taconic (Lille Skensved, Denmark). Upon arrival the rats were allowed to acclimatize for a week before the start of the experiment. The body weight of the animals at the beginning of the study was $107 \pm 9 \mathrm{~g}$ $(\mathrm{N}=28)$. The rats were housed conventionally two per cage (Macrolon, Techniplats Gazzada S. ar. L., Buguggiate, Italy) with a 12:12-h reversed light/dark cycle from 7 p.m. to 7 a.m. The room temperature was $22 \pm 1^{\circ} \mathrm{C}$ and the relative humidity $55 \% \pm 5 \%$. In their cages, the rats were given ad libitum a standard diet (Altromin rat No.1324, Brogården, Gentofte, Denmark) and citric acid acidified tap water (to avoid microbiological contamination of drinking water). The animal study was performed under conditions approved by Danish Agency of Protection of Experimental Animals and the in-house Animal Welfare Committee.

The rats were randomly divided in three groups and received either an aqueous solution of $11.5 \mathrm{mg} / \mathrm{ml}$ PVP (vehicle control, $\mathrm{N}=9)$, $\operatorname{AgNPs}(\mathrm{N}=9)$ or $\operatorname{AgAc}(\mathrm{N}=7)$ by oral gavage twice a day for 28 days. Additionally, one rat was included in each of the vehicle control, the AgNP and the AgAc groups, respectively, for tissue sampling 
for electron microscopy. The dosing volume was $10 \mathrm{ml} /$ $\mathrm{kg}$ b.w. The aqueous solution of PVP was chosen as a vehicle control because the same solution was used as stabilizer for the AgNPs. PVP was also added to the AgAc solution $\left(\mathrm{AgC}_{2} \mathrm{H}_{3} \mathrm{O}_{2}\right.$, CAS number 563-63-3, ReagentPlus, Sigma Aldrich, Denmark) to a concentration of $11.5 \mathrm{mg} / \mathrm{ml}$. The AgAc solution remained clear and colorless throughout the duration of the study indicating that silver did not precipitate or become reduced. The daily dose of silver in the AgNP and AgAc group was $9.0 \mathrm{mg} / \mathrm{kg}$ b.w.

In week three of the 28-day study the rats were individually placed in metabolism cages for $24 \mathrm{~h}$ for the collection of urine and feces in tubes on dry ice. During this time the animals had free access to water but not to feed in order to eliminate the risk of contamination of urine and feces samples.

\section{Sample preparation}

On day 29 of the study the rats fasted overnight, were anaesthetized by $\mathrm{CO}_{2} / \mathrm{O}_{2}$, and decapitated. Blood from the neck wound was collected on heparin and plasma was prepared by centrifugation $\left(1000 \times g\right.$ at $0-4^{\circ} \mathrm{C}$ for 10 minutes) and necropsy was performed. The brain was removed, weighed, transferred to ice-cold $0.32 \mathrm{M}$ sucrose and homogenized at $0-4^{\circ} \mathrm{C}$. Samples from the stomach (part of corpus ventriculi), liver (lowest part of the left median lobe), kidney (part of the right kidney), lungs (right median lobe), and muscle (right biceps femoris) were taken from five to six animals per group and frozen for later ICP-MS analysis. Furthermore, samples from the liver, ileum, and kidney were fixed in $4 \%$ neutral buffered formalin for 24 hours and embedded in paraffin. For all rats samples were taken from the same parts of the organs, namely the lowest part of the left and right lateral lobe of the liver, the part of the ileum directly above the ileo-caecal junction and a cross section of the right kidney at the level of the renal papilla. Paraffin sections of $3 \mu \mathrm{m}$ thickness were obtained by use of a microtome, collected on Superfrost plus slides (Menzel-Gläser, Germany), and oven dried overnight at $37^{\circ} \mathrm{C}$.

\section{Determination of silver concentrations in tissue, blood plasma, urine, and feces by ICP-MS}

Thawed subsamples of approximately $250 \mathrm{mg}$ tissue (stomach, liver, kidney, lungs, and muscle) and approximately $200 \mu \mathrm{l}$ of brain homogenate, urine, and blood plasma were analyzed for their silver concentration. Additionally, formalin-fixed tissue from the small intestine was analyzed. The mesenteric fat was dissected from the small intestine (sectioned between the pylorus and the caecum) and the was sample transversally divided in halves, which were analyzed separately. The whole amount of collected feces per animal was dried in an oven for $60 \mathrm{~h}$ at $80^{\circ} \mathrm{C}$ and homogenized. A dry matter content of $40 \pm 4 \% \mathrm{w} / \mathrm{w}(\mathrm{N}=8)$ was determined by weighing the feces before and after the drying procedure; $10 \mathrm{mg}$ of the dried feces were analyzed in duplicates. One sample was taken for analysis by scanning electron microscopy (SEM).

For assurance of the analytical accuracy the certified reference materials (CRM) Dogfish Liver DOLT-4 (NRC-CNRC, Canada) with a certified value for silver of $930 \pm 70 \mathrm{ng} / \mathrm{g}$ was included in the analysis. The dry matter content of the reference material was $93.4 \% \mathrm{w} / \mathrm{w}$. The average determined silver concentration was $997 \pm$ $47 \mathrm{ng} / \mathrm{g}(\mathrm{N}=30)$ which did not deviate from the certified value. For feces samples the analytical accuracy was controlled by recovery of silver standard spiked to samples because no CRM with a certified silver concentration at the $100 \mu \mathrm{g} / \mathrm{g}$ concentration level was available. The recovery was $106 \pm 2 \%(\mathrm{~N}=3)$.

Deionized water and $0.32 \mathrm{M}$ sucrose (for the brain homogenates) was analyzed as blank samples to ensure that no contamination by silver from these sources occurred during sample preparation.

All samples were digested using $3 \mathrm{ml}$ concentrated nitric acid at elevated temperature and pressure $\left(\sim 250^{\circ} \mathrm{C} ; \sim 70\right.$ bar) as described previously. Following digestion, $3 \mathrm{ml}$ of concentrated hydrochloric acid (PlasmaPure, SCP Science, Quebec, Canada) were added. For formalin-fixed tissue, $5 \mathrm{ml}$ of nitric and $5 \mathrm{ml}$ hydrochloric acid (added after digestion) were used because of the larger sample size (around $600 \mathrm{mg}$ ). Preliminary studies (data not included) showed that incomplete recoveries were obtained for silver added to the CRM Bovine Liver 1577a (NIST, Gaithersburg, MD, USA) spiked at $4 \mu \mathrm{g} / \mathrm{g}$ if no $\mathrm{HCl}$ was added after digestion. The excess chloride facilitated the formation of soluble silver chloride complexes, thus preventing precipitation of insoluble $\mathrm{AgCl}$ by reaction with chloride naturally present in the biological material.

The digests were further diluted with $2 \% \mathrm{v} / \mathrm{v}$ nitric acid to a final acid concentration of $8-12 \% \mathrm{v} / \mathrm{v}$. The measurements were performed as described above. The limit of detection was estimated at 0.7 to $2.0 \mathrm{ng} / \mathrm{g}$ in the biological samples and for feces at $200 \mathrm{ng} / \mathrm{g}$.

The silver contents were compared using Student's two sample t-test $(\mathrm{p}<0.05)$ after F-test of the equality of variances using an Excel spreadsheet (Microsoft Corp., WA, USA).

\section{Autometallography (AMG)}

After deparaffinization of the sections with xylene and rehydration through a series of ethanol-water washes, the slides were placed in jars filled with AMG developer [19]. The jars were transferred to a $26^{\circ} \mathrm{C}$ water bath covered with a dark hood. After 60 min the AMG development 
was stopped by replacing the developer with a $5 \% \mathrm{w} / \mathrm{v}$ sodium thiosulphate solution and leaving it for $10 \mathrm{~min}$. Next, the sections were rinsed in running water for several minutes followed by a rinse in distilled water. Finally, the sections were counterstained with $0.1 \% \mathrm{~m} / \mathrm{v}$ toluidine blue solution, dehydrated in ethanol-water washes, and after a xylene wash were embedded in mounting medium and covered with glass cover slips. Sections of control animals were always included.

\section{Animals and sample preparation for transmission and scanning electron microscopy}

The rats were pre-anaesthetised with inhalation of Halothane 3\% (Halocarbon Laboratories, River Edge, NJ, USA). Anaesthesia was induced by doses of a 9:1 mixture of Ketamine $25 \mathrm{mg} / \mathrm{ml}$ (Pfizer, Ballerup, Denmark) $90 \mathrm{mg} / \mathrm{kg}$ b.w. and Xylazine $20 \mathrm{mg} / \mathrm{ml}$ (Rompun ${ }^{\circledR}$ Vet. BAYER, Leverkusen, Germany) $10 \mathrm{mg} / \mathrm{kg}$ b.w. The rats were fixed by vascular perfusion through the left ventricle of the heart with $2 \% \mathrm{v} / \mathrm{v}$ glutaraldehyde in $0.05 \mathrm{M}$ sodium phosphate buffer ( $\mathrm{pH} \mathrm{7.2)} \mathrm{for} 5 \mathrm{~min}$. After fixation the animals were stored in the same fixative. Following isolation of suitable specimen blocks, the samples were rinsed three times in $0.15 \mathrm{M}$ sodium cacodylate buffer ( $\mathrm{pH}$ 7.2) and subsequently postfixed in $1 \% \mathrm{w} / \mathrm{v}$ OsO4 in $0.12 \mathrm{M}$ sodium cacodylate buffer ( $\mathrm{pH} 7.2$ ) for $2 \mathrm{~h}$. Furthermore, samples with no osmium post-fixation were included. The specimens were dehydrated in graded series of ethanol, transferred to propylene oxide and embedded in Epon according to standard procedures [20]. Sections of approximately 50 to $60 \mathrm{~nm}$ thickness were cut with a Reichert-Jung Ultracut E microtome and collected on copper grids with Formvar supporting membranes. Sections were left unstained or stained with uranyl acetate and lead citrate.

An aqueous feces extract was obtained by the following procedure: $2 \mathrm{ml}$ of deionized water were added to $400 \mathrm{mg}$ of wet feces and carefully shaken until a slurry was formed. The slurry was centrifugated for $10 \mathrm{~min}$ at 4,700 rpm $(4,224 \times g)$ in a Sigma $3-18$ K centrifuge (Sigma, Germany) to remove coarse feces constituents. Subsequently $700 \mu \mathrm{l}$ of the supernatant were transferred to Eppendorf tubes and further centrifugated for $10 \mathrm{~min}$ at $13,400 \mathrm{rpm}$ $(12,100 \times g)$ in a micro centrifuge (Eppendorf MiniSpin, Eppendorf AG, Hamburg, Germany). For TEM analysis $200 \mu \mathrm{l}$ of the supernatant were taken and diluted two times with deionized water.

The samples were examined with a Philips CM 100 TEM (Philips, Eindhoven, The Netherlands) operated at an accelerating voltage of $80 \mathrm{kV}$ and equipped with a SIS MegaView2 or an OSIS Veleta digital slow scan $2 \mathrm{k} \times 2 \mathrm{k}$ CCD camera. Digital images were recorded with the analySIS or ITEM software packages and further processed using Adobe Photoshop software (Adobe Systems
Incorporated, San Jose, California, CA, USA) to enhance contrast and brightness.

Analysis of the elemental composition was performed by use of a Tecnai T20 TEM (FEI, Eindhoven, The Netherlands) operated at $120 \mathrm{kV}$ and equipped with an INCA energy dispersive $\mathrm{x}$-ray spectrometer (Oxford instruments, Oxfordshire, UK). Analyses were performed with a focused electron probe with an accelerating voltage of $120 \mathrm{kV}$, a $14^{\circ}$ tilt, and a counting time of $100 \mathrm{~s}$. For high resolution imaging an accelerating voltage of $200 \mathrm{kV}$ was applied.

Dried feces was analyzed by a Philips XL 30 FEG scanning electron microscope (FEI, Eindhoven, Netherlands) operated in the backscattered-electron mode at an accelerating voltage of $20 \mathrm{kV}$.

\section{Results and discussion \\ Characterization and stability study of the silver nanoparticle suspension}

The size distribution of the AgNPs was determined by DLS (Figure 1a). During the time from the production of the AgNPs until the termination of the animal study the stability of the suspension was monitored by DLS to assure that the NPs were well dispersed during the 28 days duration of the animal experiment (Figure 1b). The volume distribution of the hydrodynamic size of the nanoparticles showed two peaks. The first peak (approximately $90 \%$ of the particle volume) had its maximum at $14 \pm 2 \mathrm{~nm}$ with a peak width of $4 \pm 1 \mathrm{~nm}$ (Figure 1a), whereas the second peak had its maximum at $50 \pm 9 \mathrm{~nm}$ with a peak width of $42 \pm 3 \mathrm{~nm}(\mathrm{~N}=5)$. The second peak represents approximately $11 \%$ of the total volume of nanoparticles, but less than $0.1 \%$ of the total particle number.

TEM was used as a second technique to confirm the nanoparticle sizes obtained by DLS and to obtain information about the particle shape. The nanoparticle diameters observed by TEM were in agreement with the DLS results, but no quantitative analysis was performed with the former technique. As seen in the transmission electron micrograph, (Figure 1a) the nanoparticles had an almost spherical shape and the observed larger size fraction consisted of distinct nanoparticles, and no aggregates of AgNPs were detected.

The zeta potential of the nanoparticles was around -2 $\mathrm{mV}$ at a suspension $\mathrm{pH}$ of 5.9. Electrostatic stabilization of NPs would typically require a zeta potential above $30 \mathrm{mV}$ or below $-30 \mathrm{mV}$ [21]. Accordingly, the stability of the AgNP suspension was solely based on steric stabilization by the PVP polymer. In contrast to electrostatic stabilization, steric stabilization with polymers or proteins is independent of $\mathrm{pH}$ and electrolyte concentration. Accordingly, steric stabilization is useful for prevention of agglomeration of nanoparticles in physiological media [21]. 

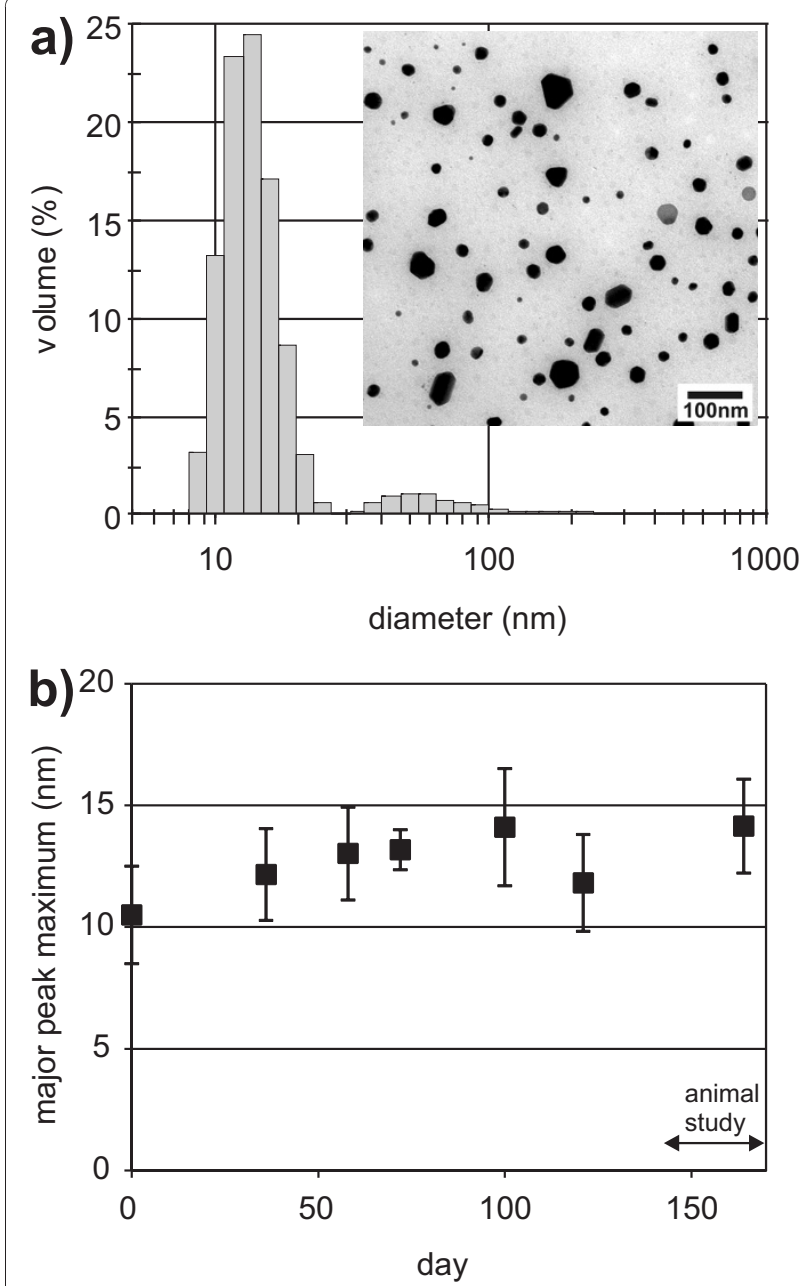

Figure 1 Size characterization and stability study of the silver nanoparticle suspension. a) Volume size distribution of the silver nanoparticles determined by dynamic light scattering on day 23 of the 28-day animal study and transmission electron micrograph of the silver nanoparticle suspension, b) Diameter value of the major peak (peak maximum; mean \pm 1 s.d., $N=5$ ) of the size distribution recorded before and during the animal study.

The total silver concentration in the suspensions as determined by ICP-MS of microwave-assisted nitric acid digested samples was $628 \pm 55 \mu \mathrm{g} / \mathrm{ml}(\mathrm{N}=16)$, which was higher than the nominal concentration of $450 \mu \mathrm{g} / \mathrm{ml}$. Rats were dosed twice a day with $10 \mathrm{ml} / \mathrm{kg} \mathrm{b.w.} \mathrm{of} \mathrm{the}$ AgNP suspension, resulting in a daily silver dose of 12.6 $\mathrm{mg} / \mathrm{kg}$ b.w. Because the dose of silver acetate was calculated based on the nominal concentration of the AgNP suspension $(450 \mu \mathrm{g} / \mathrm{ml})$, the dose of silver as AgAc at $9 \mathrm{mg} / \mathrm{kg}$ b.w. was less than that of the AgNPs.

Most research dealing with the toxicity of silver nanoparticles ignores the possible presence of ionic silver in the nanoparticle suspension. However, we aimed to quantify the proportion of silver in the AgNP suspension not present as nanoparticles. Separation of the AgNPs from the suspension by centrifugation through $12.5 \mathrm{kDa}$ cut-off filters showed that $70 \pm 1 \mu \mathrm{g} / \mathrm{ml}(\mathrm{N}=3)$ was present in the filtrate, corresponding to $11 \%$ of the total silver concentration. Ultracentrifugation was used to verify the results from the ultrafiltration experiment and to rule out the possibility that silver adhered to the ultrafiltration membrane. The silver concentration in the supernatant from the centrifugation was $65 \mu \mathrm{g} / \mathrm{ml}$, which confirmed the result of the ultrafiltration experiment. Consequently, the dose per animal of this fraction of silver was approximately $1 \mathrm{mg} \mathrm{Ag/kg} \mathrm{b.w./day,} \mathrm{and}$ remained stable over a time period of at least nine months. The observation that $11 \%$ of the total silver concentration was not present as nanoparticles despite purification of the AgNP suspension after synthesis was in agreement with a former study [22]. This study showed by use of a dialysis tube that PVP-coated silver nanoparticles in $5^{\circ} \mathrm{C}$ water released $10 \%$ of the silver in ionic form within approximately 25 days. No further dissolution was observed during the monitored time period of approximately 60 days. In the present study the first filtration experiments were performed one month after synthesis. The suspensions were stored at $4^{\circ} \mathrm{C}$ throughout the duration of the study. Therefore, the detected silver after filtration and ultracentrifugation could be ionic silver which was released after the synthesis of the AgNPs.

The results demonstrated that a well-characterized nanoparticle suspension was available and dosed to the rats throughout the study. The finding of a fraction of non-nanoparticulate silver in the AgNP suspension provided input to a more detailed interpretation of the findings from the animal study.

\section{Organ distribution of silver}

Figure 2 presents the silver organ concentration in AgNP and AgAc exposed rats. The silver concentration in organs of the control animals was below the limit of detection ( $2 \mathrm{ng} / \mathrm{g}$ wet tissue). In general, the organ distribution pattern of silver was similar for the two silver dosage forms, AgNPs and AgAc. The highest silver concentrations, listed in decreasing order, were found in small intestine, stomach, kidney, and liver tissues of the exposed animals. However, despite a higher oral silver exposure to the AgNP group the resulting silver concentrations in kidney, lung, muscle, brain, and plasma were lower $(\mathrm{p}<0.05)$ in comparison with the corresponding tissues from animals exposed to AgAc. When normalized to the doses of 12.6 and $9 \mathrm{mg} \mathrm{Ag} / \mathrm{kg}$ b.w./day used for the AgNP and the AgAc groups (see additional file 1 ), respectively, the silver concentrations in tissues from animals exposed to AgNPs were approximately 40-50\% of those corresponding to administration of AgAc for kidney, stomach, brain and plasma, and $10-20 \%$ for muscle and lungs. 


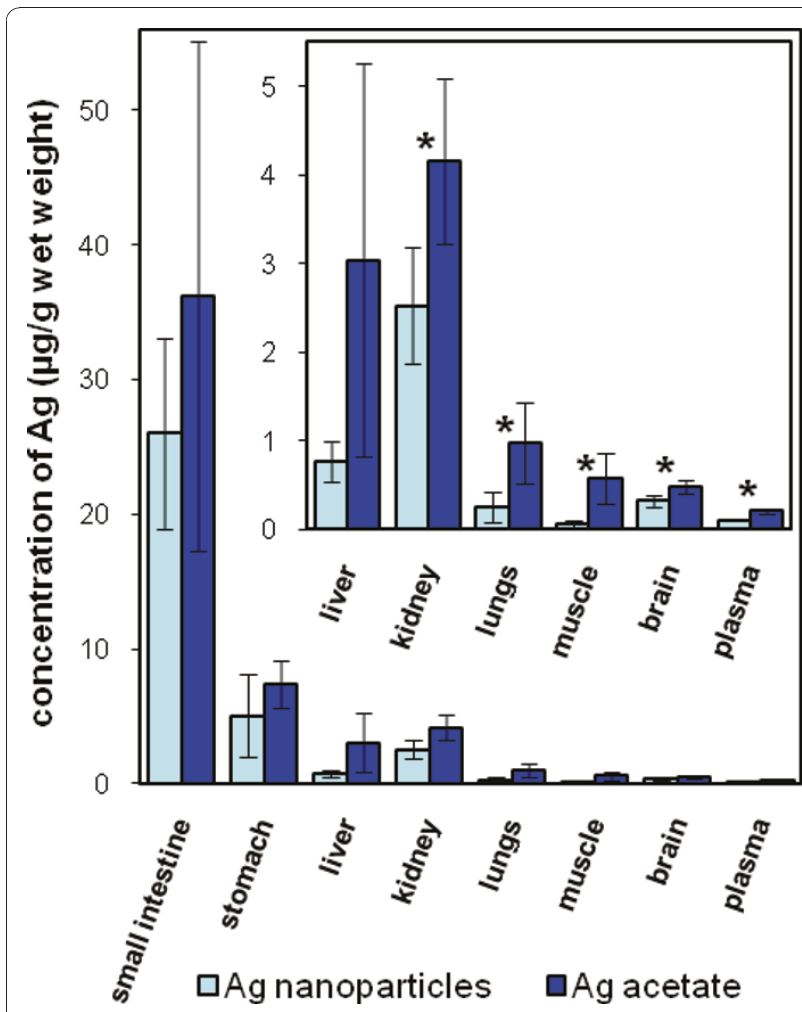

Figure 2 Silver concentration in rat organs. Silver concentrations (mean \pm 1 s.d., $N=5-7$ ) in rat organs after 28 days oral administration of silver nanoparticles and silver acetate. Statistically significant differences $(p<0.05)$ between the groups are marked with asterisks $\left(^{*}\right)$. Silver concentrations in the control animals were below the limit of detection.

This is the first direct comparison of the distribution and concentration of silver in rat organs following oral administration of AgNPs or a soluble silver salt. The distribution of silver following AgAc exposure in the present study resembled that reported in other studies where rats were orally exposed to silver chloride or silver nitrate. Silver was found to be distributed to several tissues, including liver, spleen, bone marrow, lymph nodes, skin, kidney, thyroid, heart, pancreas, adrenal glands, and brain [9]. Furthermore, the silver organ distribution pattern and concentrations of silver following exposure to AgNPs in the present study were comparable to the results from a 28 -day study where $30 \mathrm{mg} / \mathrm{kg}$ b.w./day AgNPs of $60 \mathrm{~nm}$ in diameter and stabilized with carboxymethylcellulose were administered orally to rats [13]. The fact that similar silver concentrations were found in the same organs in both studies was surprising because the dose in the published study [13] was twice as high as that used in the present study. This observation could be explained by a lower absorption rate of silver from the five times larger carboxymethylcellulose-stabilized AgNPs [13]. Furthermore, an influence of the different stabilizing agents on the absorption of the nanoparticles is possible [12].

The relatively large standard deviation for silver in small intestine and liver tissues (Figure 2) was caused by inter-animal variation. Such variation could indicate that despite the same dose per $\mathrm{kg}$ body weight, variations in factors such as the intestinal flora and passage time may have an influence on how much silver is actually taken up.

Since $11 \%$ of the total silver in the AgNP suspension was present in another form than nanoparticles, it was possible to consider that only this fraction was absorbed by the intestine. The non-nanoparticulate form of silver in the AgNP suspension correspond to a dose of $1 \mathrm{mg}$ $\mathrm{Ag} / \mathrm{kg}$ b.w./day in comparison to $9 \mathrm{mg} \mathrm{Ag} / \mathrm{kg}$ b.w./day for AgAc. Assuming similar rates of absorption, accumulation, and excretion, the expected silver concentration would in this case be nine times lower in the blood plasma and organs in comparison to blood plasma and organs from AgAc dosed animals. However, our findings demonstrated that the silver concentrations in stomach, kidney, brain, and plasma of the AgNP exposed rats were approximately one half of that found after administration of AgAc. Therefore, the silver concentration in tissues cannot be ascribed only to the non-nanoparticulate fraction of the AgNP suspensions, but must partially contain silver originating from the AgNPs.

\section{Excretion of silver}

Table 1 presents the absolute and relative amounts of silver in feces and urine after 24 hours of collection in the third week of the study. The excretion is given in both micrograms and percent of the total daily intake. The excretion of silver with urine was low $(<0.1 \%)$ whereas a high amount of silver was excreted in feces. This finding was in agreement with previous reports on excretion of silver nitrate or silver iodide after oral or intravenous administration to rats $[9,23]$.

The excretion of silver in feces was $63 \pm 23 \%(\mathrm{~N}=5)$ of the daily dose for AgNPs and $49 \pm 21 \%(\mathrm{~N}=5)$ of the daily dose for AgAc. However, given the experimental design it was not possible to provide information as to what extent silver was absorbed from the digestive tract because fecal silver may partially be a result of biliary excretion. In studies using intravenous dosing it was shown that biliary excretion of silver was high [23] and against a plasma-to-bile concentration gradient where the concentration in bile was 16 to 20 times higher than that in plasma from rats [24]. Furthermore, binding of silver to the intestinal surface could result in a decreased excretion of silver within the 24-hour collection of feces.

The non-significant difference between the fecal excretion of silver in the AgNP and AgAc groups 
Table $124 \mathrm{~h}$ excretion of silver in urine and feces

\begin{tabular}{ccccc}
\hline & urine $(\boldsymbol{\mu g})$ & feces $(\boldsymbol{\mu g})$ & urine $(\%$ of $\mathbf{2 4} \mathbf{h}$ intake) & feces $(\%$ of $\mathbf{2 4} \mathbf{h}$ intake) \\
\hline Ag-PVP nanoparticles & $0.10 \pm 0.05$ & $1190 \pm 430$ & $0.005 \pm 0.003$ & $63 \pm 23$ \\
\hline Ag acetate & $0.73 \pm 0.23$ & $610 \pm 250$ & $0.057 \pm 0.017$ & $49 \pm 21$
\end{tabular}

Absolute and relative amount of silver (mean \pm 1 s.d., $N=5$ ) excreted in urine and feces within a 24 hour time period in week 3 of the study.

suggested a higher fecal excretion of silver after oral exposure to nanoparticles. This was in accordance with the generally lower values for silver in organs of rats that received AgNPs (Figure 2). A possible explanation for a decreased absorption of AgNPs would be an enhanced binding of nanoparticles to non-digestible food components. Furthermore, the passage of the intestinal barrier of AgNPs could be inferior to that of AgAc.

Preliminary investigations of the presence of AgNPs in dried feces by SEM and of an aqueous feces extract by TEM, however, provided no evidence for the presence of AgNPs. Further work in a targeted study is therefore warranted, and should include optimization of the sample preparation methodology and examination of a larger number of samples before any definite statement about the presence or absence of intact AgNPs in the rat feces can be made.

\section{Localization of silver in the ileum}

Autometallographic staining (AMG) was used to analyze the in situ distribution of silver in the ileum tissue. In the ileum AMG revealed the presence of silver in the lamina propria mainly in the tips of the villi, whereas no silver was detected in the epithelial cell cytoplasm (Figures 3a and $3 \mathrm{~b}$ ). Furthermore, silver was present in cells in the submucosa. Sections of AgAc exposed rats showed the same distribution of silver in the ileum as observed for AgNP exposed rats (not shown). However, it must be kept in mind that AMG cannot distinguish between silver in the form of nanoparticles, metallic silver, or silver selenide and silver sulfide nanocrystals [19]. Tissue from the control animals showed no staining except for a faint non-specific background which proved that no unspecific staining occurred.

TEM was used to further characterize the silver accumulated in the intestinal tissue. In the AgNP exposed rats, mostly spherical, but strongly aggregated electrondense granules were found in the lysosomes of macrophages within the lamina propria (Figures $4 a-c$ ) and individual granules in the basal lamina of the epithelium (Figures 4d-f). In the AgAc exposed rats granules of similar size were found at the same positions within the tissue (Figure $5 \mathrm{a}$ and $5 \mathrm{~b}$ ). The diameter of the granules was approximately $12 \mathrm{~nm}$ or smaller, which was in the same size range as the majority of the administered AgNPs $(14 \pm 4 \mathrm{~nm})$. Furthermore, single granules were found randomly distributed in the connective tissue of the submucosa. No granules were observed in the microvilli or within the enterocytes, which could be due to the fact that the last dose was administered on the day before the rats were sacrificed. The investigation of unstained samples also showed electron dense granules at the different locations. Thus, artifacts caused by

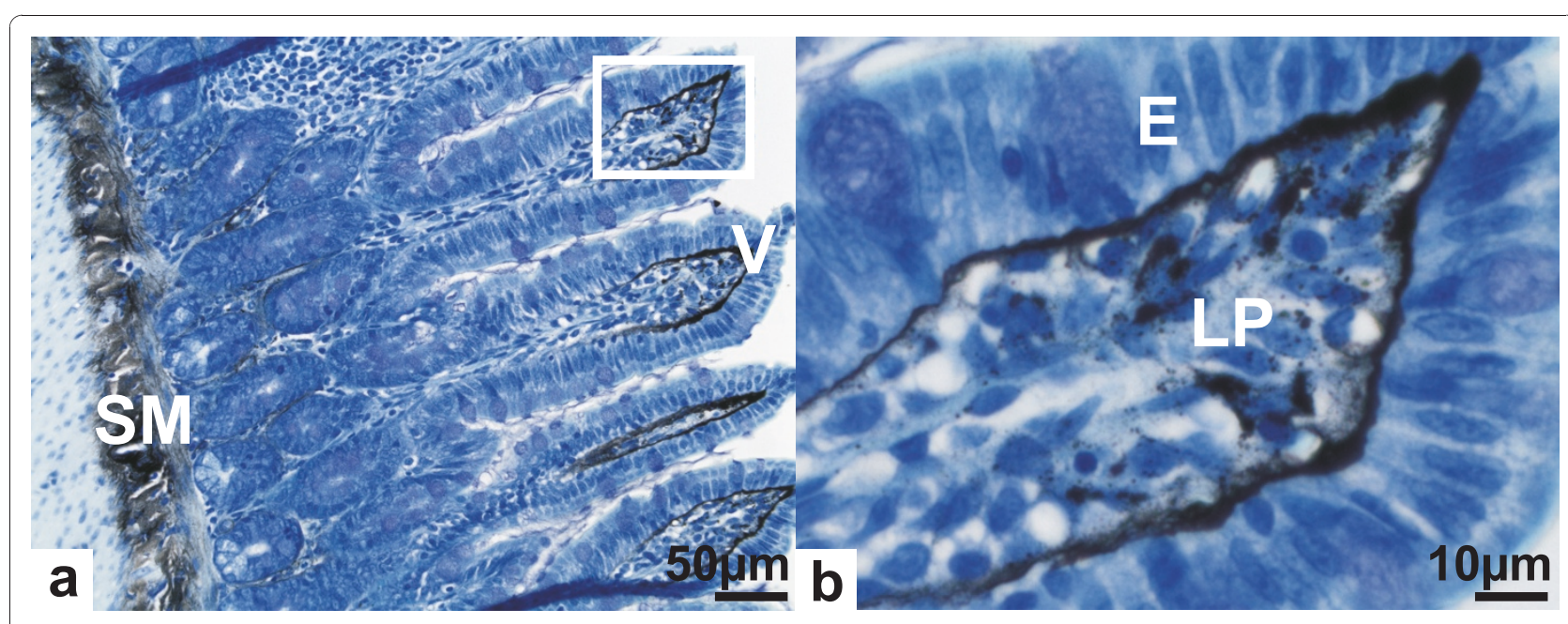

Figure 3 Autometallographic staining of ileum from a silver nanoparticle exposed rat. Optical micrographs of ileum section cuts showing, a) Overview and b) Detail with heavy staining in the tips of the intestinal villi ( $V$ ) directly below the epithelium (E), within the lamina propria $(L P)$, and in the submucosal region (SM). 

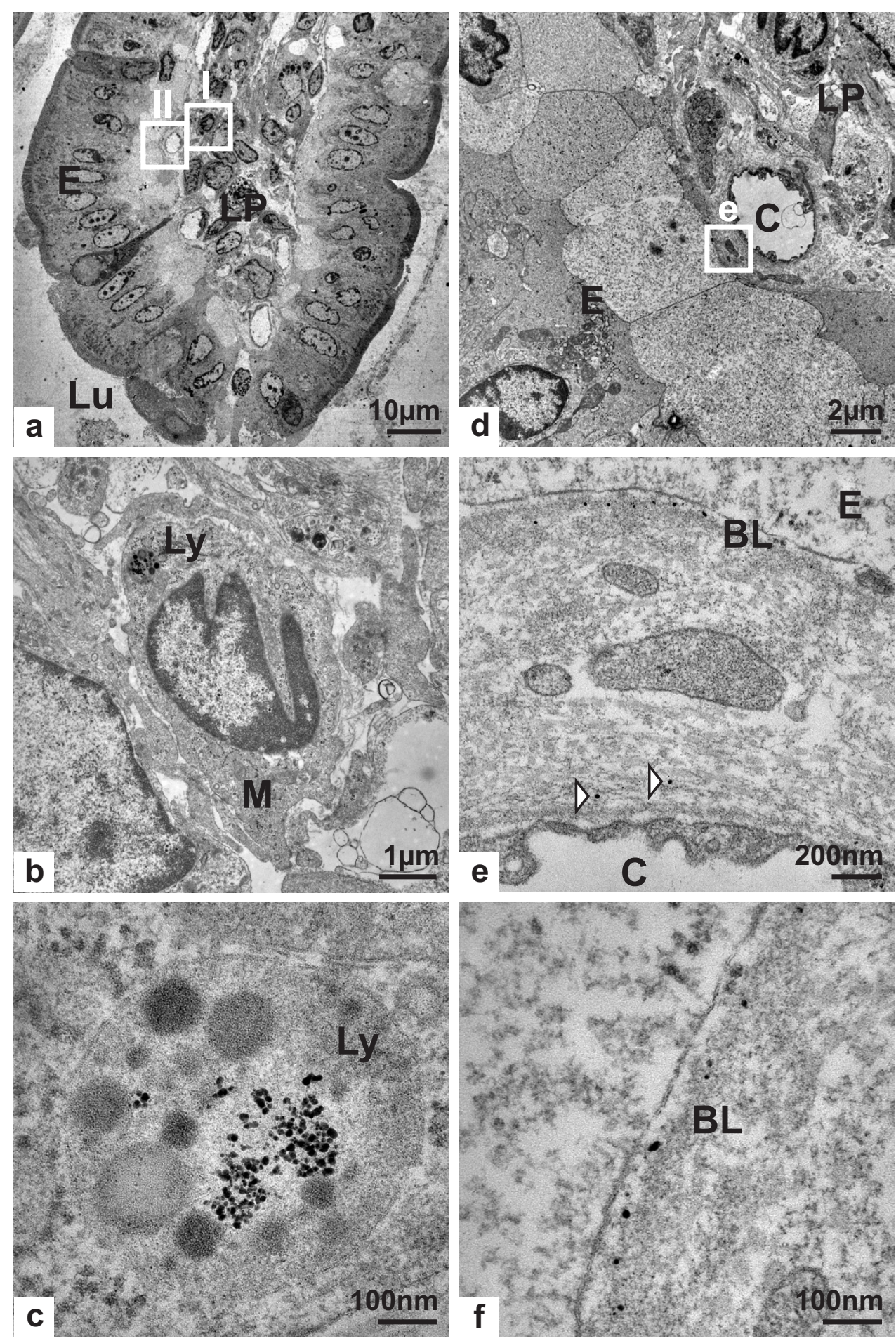

Figure 4 Transmission electron micrograph of an intestinal villus (ileum) from a silver nanoparticle exposed rat. Transmission electron micrographs of ultra-thin sections (stained with uranyl acetate and lead citrate) showing a) overview of an intestinal villus (LU = lumen) highlighting two regions of interest (I and II) in the lamina propria (LP) as well as in a region between lamina propria and the epithelium (E), respectively; b-c) details of region I showing granules in a lysosome (Ly) within a macrophage (M); $d$-f) details of region II showing granules in close proximity to a capillary (C) within the lamina propria and in the basal lamina (BL) of the epithelium. The region of interest highlighted in d) is presented in e), whereas $f$ ) is showing the basal lamina in more detail. 


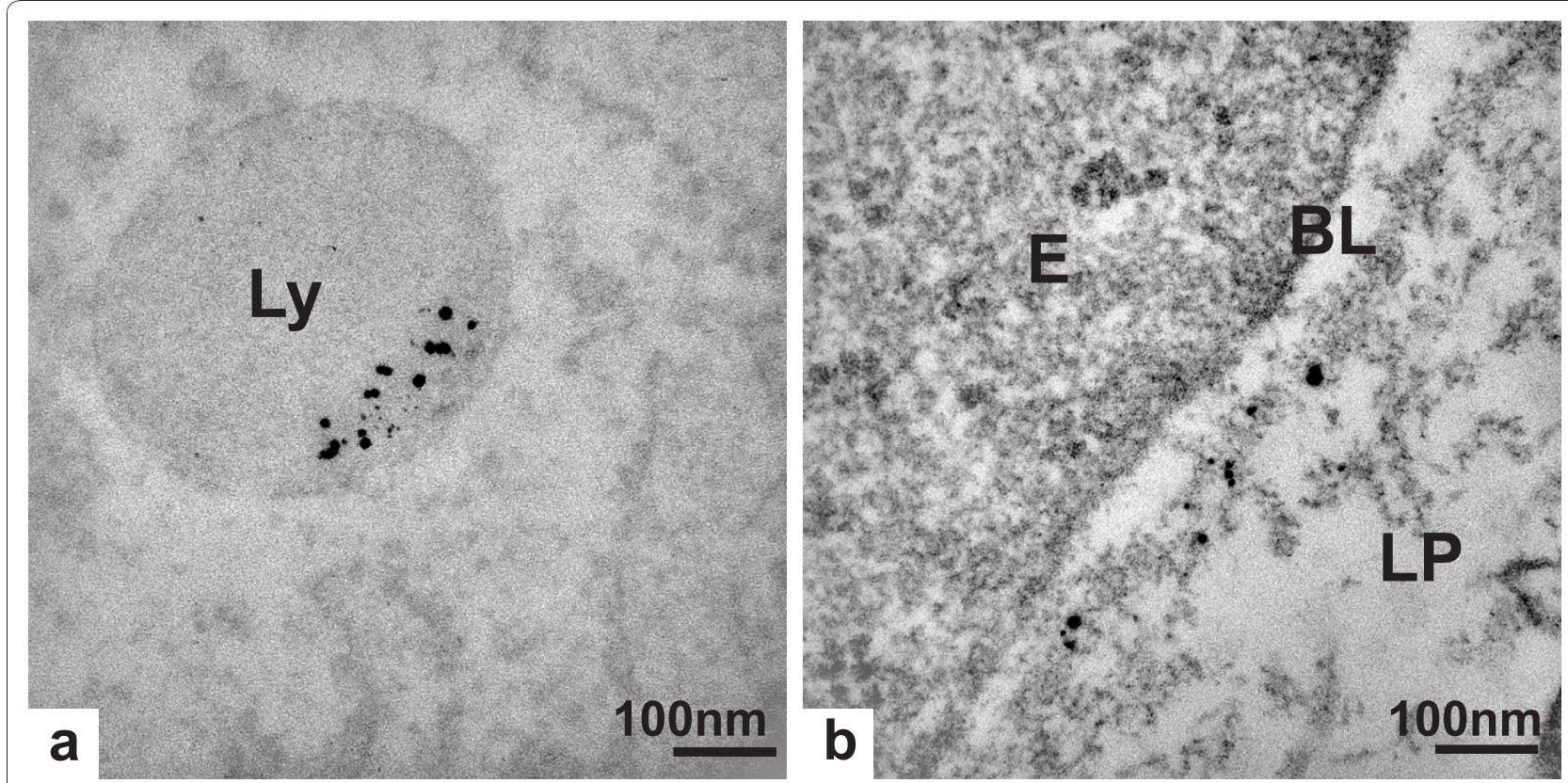

Figure 5 Transmission electron micrograph of an intestinal villus (ileum) from a silver acetate exposed rat. Transmission electron micrograph of unstained ultra-thin sections showing granules a) in a lysosome (Ly) within a macrophage in the lamina propria and b) in the basal lamina (BL) of the epithelium.

heavy metal staining with lead citrate and uranyl acetate could be excluded.

Energy dispersive $\mathrm{x}$-ray spectroscopy (EDX) was used to confirm that the observed granules in the lysosomes of macrophages indeed consisted of silver (Figure 6). In addition to silver signals corresponding to selenium and sulfur were detected. These were absent in the background spectrum which was recorded from tissue containing no granules. An osmium signal originated from the tissue fixation procedure in which osmium tetroxide was used as a postfixative. There was no qualitative difference between the elemental composition of the granules found in the AgNP and AgAc exposed rats.

The observation of sulfur or selenium containing silver granules in the tissue after dosage of AgAc was in agreement with results from other studies. Occupational exposure of humans to silver [25] or intake of silver-containing drugs $[26,27]$ was found to lead to a slate blue-gray irreversible discoloration of the skin of patients termed "argyria". In the skin, granules of typically 20 to $100 \mathrm{~nm}$ in diameter were observed which consisted of silver sulfide and silver selenide [26]. In rat studies, 30 to $90 \mathrm{~nm}$ granules were observed in the basal lamina of the renal glomeruli after administration of $0.15 \%$ aqueous silver nitrate solution in drinking water for 4 to 15 weeks $[28,29]$. The proton induced X-ray emission microanalysis of silver grains enhanced by autometallography and isolated from kidney sections of silver exposed rats showed that the granules consisted of silver and sulfur [19]. After exposing rats to $0.01 \%$ silver lactate or silver nitrate dissolved in drinking water for four weeks, AMG developed silver grains were found in neurons and glia calls, both intracellularly in lysosomes and extracellularly in basement membranes [30]. Furthermore, it has very recently been shown that silver ions are liberated in vivo from silver surfaces [31]. AMG developed silver grains were detected both extra- and intracellularly in tissues far away from the implant including regional lymph nodes, liver, kidney, and central nervous system [31]. However, the formation of selenium and sulfur containing silver granules both in the intestinal system of rats after oral exposure to AgAc or to AgNPs has not been described so far.

The presence of sulfur in the in vivo formed silver granules has been explained with the high affinity of silver and sulfur which could result in a combination of silver ions with biological structures and constituents with high sulfur content. Such examples include cystein contained in collagen fibers or sulfur-containing polyanionic glycoproteins which are particularly abundant in the basal lamina $[19,26]$. This would be in accordance with the observed deposition of granules in the basal lamina of the ileal epithelium in the present study (Figure 4f). The lysosomal accumulation of silver could be caused either by direct uptake from the external milieu such as protein-bound silver or by primary binding of silver to intracellular molecules which were subsequently engulfed and digested [30]. The presence of selenium in the silver granules has been explained by a 

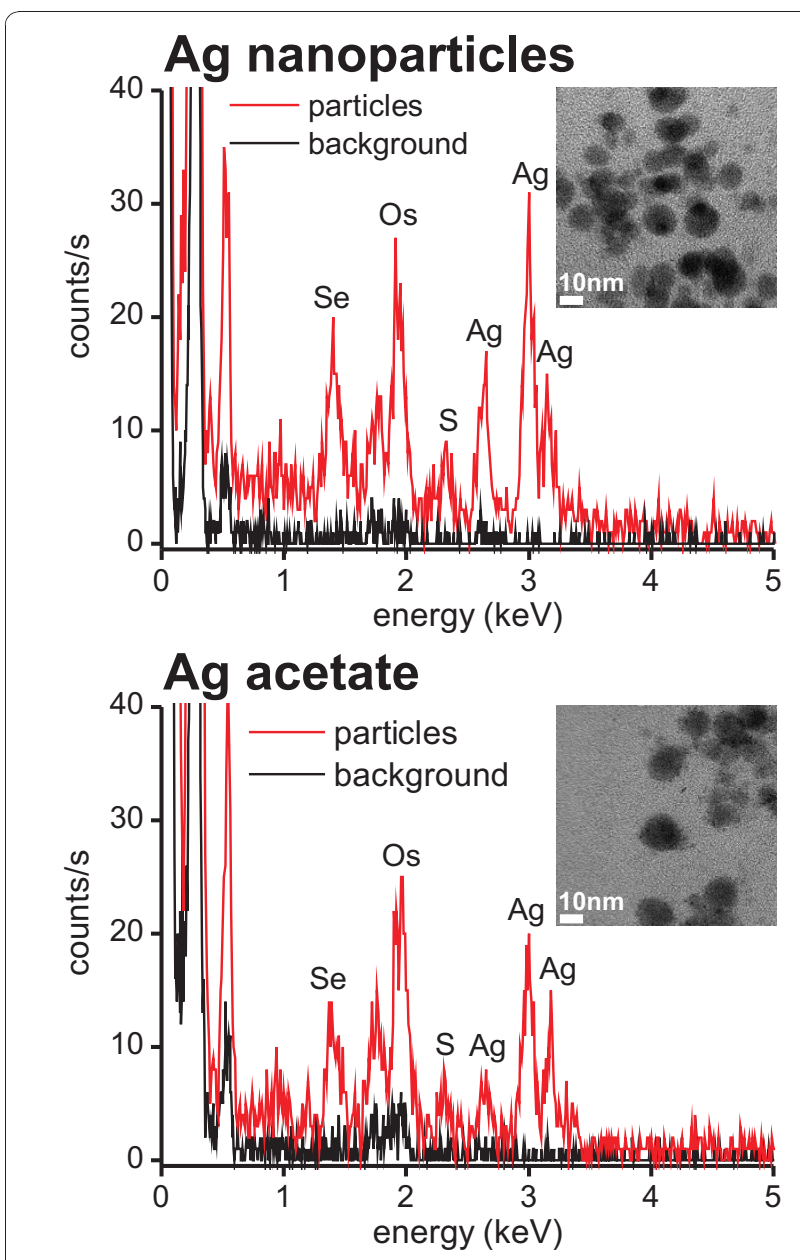

Figure 6 Energy dispersive $x$-ray emission spectra of granules in the ileum. Energy dispersive $x$-ray emission spectra of granules in lysosomes of silver nanoparticle and silver acetate exposed rats (red line) and corresponding background spectra (black line), i.e. spectra of surrounding tissue containing no visible granules

(unstained sections). The transmission electron micrographs show the analyzed granule containing area.

possible replacement of sulfur by selenium over time because of the higher chemical stability and lower solubility of silver selenide in comparison to silver sulfide $[26,32]$. Another suggested mechanism has been the direct interaction of silver with selenium bound to glutathione peroxidase (GSH-Px) [26]. The formation of the insoluble silver sulfide and selenide reduces the toxic effects of silver ions by reducing their biological availability and consequently preventing their interference with normal enzymatic activities in tissues [26,32].

The present study showed the formation of silver granules containing selenium and sulfur in lysosomes following administration of AgNPs. We suggest two possible scenarios: 1) AgNPs were dissolved in the gastrointestinal system. The silver ions bound to proteins and were deposited as granules in the lysosomes in a similar way as silver acetate. 2) Intact AgNPs were absorbed, bound to proteins and subsequently deposited in lysosomes. In the first scenario, it would be a coincidence that the re-deposited silver formed granules with a similar size as the administered silver nanoparticles. In the latter case, in would be a coincidence that the granules deposited after administration of silver acetate had a similar size as the deposited silver nanoparticles.

It is possible that the nanoparticles are taken up across the intestinal barrier as particles with diameters less than $1 \mu \mathrm{m}$ are extremely susceptible to absorption by the intestinal system [11]. Gold nanoparticles with diameters ranging from 5 to $58 \mathrm{~nm}$ were administered orally to mice. It was shown that the gastrointestinal absorption of the nanoparticles occurred paracellularly by persorption through gaps created by extruding enterocytes [33]. However, the question is whether the AgNPs remain intact in the gastrointestinal system prior to absorption.

The size distribution (Figure 1a) showed that the AgNP suspension contained a small fraction of nanoparticles equal to or larger than $50 \mathrm{~nm}$ in diameter. In contrast, nanoparticles of this size fraction were not observed in ileum by TEM despite the expected high degree of absorption of nanoparticles in this size range [34]. This suggests at least a partial dissolution of these large particles in the gastrointestinal system. Furthermore, other studies have shown that polyvinylpyrrolidone (PVP)coated AgNPs reacted with hydrochloric acid (18\%) to form insoluble $\mathrm{AgCl}$, which did not occur for bulk or coarse-grained silver [35], and that AgNPs completely dissolved in aqueous nitric acid solution at $\mathrm{pH}=0.5$ [36]. Although these experiments were not conducted under physiological conditions, they indicate that AgNPs may undergo chemical reactions and eventually dissolve in the gastrointestinal system. Further dedicated studies that focus on the stability of AgNPs in the gastrointestinal environment are therefore warranted.

\section{Localization of silver in the liver}

Using AMG, silver could also be localized in the liver tissue of the exposed rats. In the tissue from the untreated control animals no staining, except for a faint non-specific background in some sections, was observed. The large inter-animal differences in the silver concentration in the liver observed by ICP-MS analysis were confirmed by the AMG stained sections in which differences in the staining intensity of the liver sections from different animals were observed, though similar parts of the livers were investigated. The distribution pattern of silver was again similar for AgNP and AgAc exposed animals. In general an intense staining was observed around the central veins and the portal tracts (see additional file 2a). In these regions several Kupffer cells were intensely stained. 
However, there was no preferred staining of Kupffer cells in the remaining tissue. Small AMG grains were mainly observed in or around hepatocytes (see additional file $2 b)$. Whether these AMG grains were present within the hepatocytes or in the bile canaliculi could not be determined. The observations were in contrast to findings for intravenously and intraperitoneally injected gold nanoparticles which, independent of their size, were taken up primarily by the Kupffer cells in the liver [37] and could indicate that no intact silver nanoparticles were deposited in the liver. No silver granules could be detected by TEM, which could either be related to a very small size or a low number of the granules in the tissue. A few silver atoms are sufficient to be visible as AMG grains after staining [19], which might not be detectable by TEM.

\section{Localization of silver in the kidneys}

In kidney tissue silver AMG staining revealed the presence of silver in the glomeruli and proximal tubules (see additional file $3 \mathrm{a}$ ). In the proximal tubules single large AMG grains were localized along the luminal brush border of the epithelium (see additional file $3 \mathrm{~b}$ ), whereas the staining was more homogenous in the glomeruli. Furthermore, heavy staining was observed in the renal papilla and seemed to be restricted to the interstitial tissue (images not presented). Again, no difference in the silver distribution after AMG staining was observed between AgNP and AgAc exposed animals. However, on the basis of AMG staining no statement about the chemical form of the deposited silver can be made.

First investigations of an AgNP exposed rat by TEM revealed the presence of granules in the microvilli of the epithelial cells of a proximale tubule (see additional file 4), which was in agreement with the large AMG grains observed by light microscopy. The granules had an irregular shape and a relatively broad size distribution, which did not coincide with that of the administered AgNPs and could be agglomerates of the nanoparticles. Future investigations will focus on the chemical composition of these granules.

No granules were found in the basal lamina of the renal glomeruli by TEM. In studies which described the deposition of silver in the basal lamina of the renal glomeruli, animals were exposed for several weeks by adding silver to the drinking water with concentrations around $2.5 \mathrm{mg} / \mathrm{ml}$ [38]. It was found that in immature rats the deposition of silver took place much more gradually and that the granules were smaller and more sparsely distributed in comparison to adult rats [30]. This could explain the absence of granules visible by TEM in the glomerular membrane in the present study. Lung, muscle, and brain tissue were not analyzed by microscopy because of the relatively low silver concentrations in those tissues.

\section{Conclusions}

In the present study, the comparison of silver acetate and silver nanoparticles did not reveal differences with respect to the distribution pattern of silver in organs and tissues. The absolute silver concentrations in the organs were generally lower after administration of AgNPs than after administration of AgAc. This was in agreement with an indication of a higher fecal excretion of silver after administration of AgNPs, and further studies are warranted.

In the ileum of rats exposed to either AgNPs or AgAc, sulfur and selenium containing silver granules of similar size and shape were found in lysosomes of macrophages. The deposited granules resulting from both tested forms of silver were in the same size range as the administered silver nanoparticles. The coinciding size ranges however, hampered the identification of the absorption mechanism of the nanoparticles. Further studies will be necessary to investigate whether silver nanoparticles are absorbed as an entity or whether they dissolve in the gastrointestinal system followed by re-deposition in the tissues. The accumulation of silver from AgAc and from AgNPs points to lysosomes as a likely target for adverse effects.

In the design of future nanotoxicity studies using oral administration of nanomaterials to laboratory animals, the possible dissolution of the nanoparticulate test material in the gastrointestinal system should be taken into account. Furthermore, inclusion of a non-nanoparticulate counterpart to the tested nanomaterial for comparison of toxicity is advisable.

\section{Additional material}

\footnotetext{
Additional file 1: Normalized silver concentrations in rat organs. Silver concentrations $(N=5-6)$ in the rat organs after normalization to the doses of 12.6 and $9 \mathrm{mg} \mathrm{Ag} / \mathrm{kg}$ b.w./day administered to the AgNP and the AgAc group, respectively, as well as the ratio between mean silver organ concentrations in the AgNP and AgAc groups (marked as dots). Statistically significant difference $(p<0.05)$ between the groups is marked with asterisks $\left(^{*}\right)$.

Additional file 2: Autometallographic (AMG) staining of liver from an AgNP exposed rat. a) Portal triad with heavy staining in Kupffer cells and around the blood vessels b) AMG grains scattered around hepatocytes

Additional file 3: Autometallographic (AMG) staining of kidney from an AgNP exposed rat. a) Heavy staining of the glomeruli b) AMG grains in a proximal tubule

Additional file 4: Transmission electron micrograph of a renal proximal tubule from an AgNP exposed rat. TEM images of ultra-thin sections (stained with uranyl acetate and lead citrate) of kidney a) Overview of a proximal tubule with the region of interest shown in b); b) ensemble of granules in the microvilli of the epithelia cells; $c-d$ ) higher magnification of the granules.
} 


\section{Acknowledgements}

The authors would like to thank Mary-Ann Gleie (Department of Biomedical Sciences, University of Copenhagen) for sample preparation for transmission electron microscopy; Majken Sand (Institute of Anatomy, University of Aarhus) for supporting the AMG staining; Birgitte Koch Herbst (Division of Food Chemistry, National Food Institute, Technical University of Denmark) for helping with sample preparation and ICP-MS measurements, as well as the technicians Annette Landin, Joan Frandsen and Karen Roswall and the head of the animal facilities Anne Ørngren (Division of Toxicology, National Food Institute, Technical University of Denmark). Keld Alstrup Jensen is thanked for giving access to the Dynamic Light Scattering equipment at the National Research Centre for the Working Environment and Blake Tutterow (Purdue University) for proof reading of the manuscript. Finally, we thank The Danish Food Industry Agency for project funding and DHI, Denmark for co-financing the project.

\section{Author details}

'Division of Food Chemistry, National Food Institute, Technical University of Denmark, Søborg, Denmark. 'Division of Toxicology and Risk Assessment, National Food Institute, Technical University of Denmark, Søborg, Denmark. ${ }^{3}$ Department of Biomedical Sciences, The Panum Institute, University of Copenhagen, Copenhagen N, Denmark. ${ }^{4}$ Department of Neurobiology, Institute of Anatomy, University of Aarhus, Aarhus C, Denmark. ${ }^{5}$ Lab for BioEnvironmental Effects of Nanomaterials and Nanosafety, Institute of High Energy Physics, Chinese Academy of Sciences, Beijing, China. ${ }^{6}$ The Nanotoxicology and Occupational Hygiene Group, National Research Centre for the Working Environment, Copenhagen $\varnothing$, Denmark. ${ }^{7}$ Human Health and Safety, DHI, Hørsholm, Denmark.

\section{Authors' contributions}

$\mathrm{KL}$ carried out the silver organ distribution study, the light and transmission electron microscopy analysis, dynamic light scattering measurements, and drafted the manuscript. $\mathrm{NH}$ was involved in design and execution of the animal study. KQ was responsible for TEM sample preparation and supported interpretation of the TEM images. AL provided the AMG staining method and revised the manuscript. XG was responsible for preparation of the AgNPs and contributed to the nanoparticle characterization. UV has revised the manuscript. AM was responsible for the design and conduction of the animal study, participated in light microscopy analysis of AMG developed tissue cuts, and revised the manuscript. HRL contributed to the design of the study and revised the manuscript. EHL contributed to design and coordination of the present study and revised the manuscript. All authors read and approved the final manuscript.

\section{Competing interests}

The authors declare that they have no competing interests.

Received: 21 December 2010 Accepted: 1 June 2011

Published: 1 June 2011

\section{References}

1. Hansen SF, Michelson ES, Kamper A, Borling P, Stuer-Lauridsen F, Baun A: Categorization framework to aid exposure assessment of nanomaterials in consumer products. Ecotoxicology 2008, 17:438-447.

2. Kim JS, Kuk E, Yu KN, Kim JH, Park SJ, Lee HJ, et al: Antimicrobial effects of silver nanoparticles. Nanomedicine: Nanotechnology, Biology and Medicine 2007, 3:95-101.

3. Lok CN, Ho CM, Chen R, He QY, Yu WY, Sun H, et al: Silver nanoparticles: partial oxidation and antibacterial activities. Journal of Biological Inorganic Chemistry 2007, 12:527-534.

4. Chen X, Schluesener HJ: Nanosilver: A nanoproduct in medical application. Toxicology Letters 2008, 176:1-12.

5. nanotechproject.org: Woodrow Wilson International Centre for Scholars, Project on Emerging Nanotechnologies, Consumer Products Inventory of Nanotechnology Products. 2009 [http://www.nanotechproject.org/ inventories/consumer/, Ref Type: Electronic Citation.

6. Chaudhry Q, Scotter M, Blackburn J, Ross B, Boxall A, Castle L, et al: Applications and implications of nanotechnologies for the food sector. Food Additives \& Contaminants: Part A: Chemistry, Analysis, Control, Exposure \& Risk Assessment 2008, 25:241-258.
7. Ahmadi J: Application of Different Levels of Silver Nanoparticles in Food on the Performance and Some Blood Parameters of Broiler Chickens. World Applied Sciences Journal 2009, 7:24-27.

8. Fondevila M, Herrer R, Casallas MC, Abecia L, Ducha Jj: Silver nanoparticles as a potential antimicrobial additive for weaned pigs. Animal Feed Science and Technology 2009, 150:259-269.

9. ATSDR: Toxicological Profile for Silver. 1990. Agency for Toxic Substances and Disease Registry, U.S. Department of Health and Human Services, Public Health Service., Ref Type: Report.

10. Wijnhoven SWP, Peijnenburg WJGM, Herberts CA, Hagens WI, Oomen AG, Heugens EHW, et al: Nano-silver - a review of available data and knowledge gaps in human and environmental risk assessment. Nanotoxicology 2009, 3:109-138.

11. Florence AT: The Oral Absorption of Micro- and Nanoparticulates: Neither Exceptional Nor Unusual. Pharmaceutical Research 1997, 14:259-266.

12. Florence AT: Nanoparticle uptake by the oral route: Fulfilling its potential? Drug Discovery Today: Technologies 2005, 2:75-81.

13. Kim YS, Kim JS, Cho HS, Rha DS, Kim JM, Park JD, et al: Twenty-Eight-Day Oral Toxicity, Genotoxicity, and Gender-Related Tissue Distribution of Silver Nanoparticles in Sprague-Dawley Rats. Inhalation Toxicology: International Forum for Respiratory Research 2008, 20:575-583.

14. Tang J, Xiong L, Wang S, Wang J, Liu L, Li J, et al: Distribution, Translocation and Accumulation of Silver Nanoparticles in Rats. Journal of Nanoscience and Nanotechnology 2009, 9:4924-4932.

15. Garza-Ocañas L, Ferrer DA, Burt J, Diaz-Torres LA, Ramirez Cabrera M, Tamez Rodriguez $V$, et al: Biodistribution and long-term fate of silver nanoparticles functionalized with bovine serum albumin in rats. Metallomics 2010.

16. Zhang Z, Zhao B, Hu L: PVP Protective Mechanism of Ultrafine Silver Powder Synthesized by Chemical Reduction Processes. Journal of Solid State Chemistry 1996, 121:105-110.

17. Bernhardt C: Particle Size Analysis: Classification and sedimentation methods London: Chapman \& Hall; 1994.

18. Johnson PB, Christy RW: Optical Constants of the Noble Metals. Phys Rev B 1972, 6:4370.

19. Danscher G, Stoltenberg M: Silver enhancement of quantum dots resulting from (1) metabolism of toxic metals in animals and humans, (2) in vivo, in vitro and immersion created zinc-sulphur/zinc-selenium nanocrystals, (3) metal ions liberated from metal implants and particles. Progress in Histochemistry and Cytochemistry 2006, 41:57-139.

20. Maunsbach AB, Afzelius BA: Biomedical Electron Microscopy Academic Press; 1999.

21. Bihari P, Vippola M, Schultes S, Praetner M, Khandoga A, Reichel C, et al: Optimized dispersion of nanoparticles for biological in vitro and in vivo studies. Particle and Fibre Toxicology 2008, 5:14.

22. Kittler S, Greulich C, Diendorf J, Köller M, Epple M: Toxicity of Silver Nanoparticles Increases during Storage Because of Slow Dissolution under Release of Silver lons. Chemistry of Materials 2010, 22:4548-4554.

23. Gregus Z, Klaassen CD: Disposition of metals in rats: A comparative study of fecal, urinary, and biliary excretion and tissue distribution of eighteen metals. Toxicology and Applied Pharmacology >1986, 85:24-38.

24. Klaassen CD: Biliary excretion of silver in the rat, rabbit, and dog. Toxicology and Applied Pharmacology 1979, 50:49-55.

25. Bleehen SS, Gould DJ, Harrington CI, Durrantte, Slater DN, Underwood JCE: Occupational argyria; light and electron microscopic studies and X-ray microanalysis. British Journal of Dermatology 1981, 104:19-26.

26. Massi D, Santucci M: Human Generalized Argyria: A Submicroscopic and X-Ray Spectroscopic Study. Ultrastructural Pathology 1998, 22:47-53.

27. Jonas L, Bloch C, Zimmermann R, Stadie V, Gross GE, Schäd SG: Detection of Silver Sulfide Deposits in the Skin of Patients with Argyria After Longterm Use of Silver-containing Drugs. Ultrastructural Pathology 2007, 31:379-384.

28. Walker F: The deposition of silver in glomerular basement membrane Virchows Archiv B Cell Pathology Zell-pathologie 1972, 11:90-96.

29. Creasey M, Moffat DB: The deposition of ingested silver in the rat kidney at different ages. Cellular and Molecular Life Sciences 1973, 29:326-327.

30. Rungby J, Danscher G: Localization of exogenous silver in brain and spinal cord of silver exposed rats. Acta Neuropathologica 1983, 60:92-98.

31. Danscher $G$, Locht $L$ : In vivo liberation of silver ions from metallic silver surfaces. Histochemistry and Cell Biology 2010, 133:359-366. 
32. Sato S, Sueki H, Nishijima A: Two unusual cases of argyria: the application of an improved tissue processing method for X-ray microanalysis of selenium and sulphur in silver-laden granules. British Journal of Dermatology 1999, 140:158-163.

33. Hillyer JF, Albrecht RM: Gastrointestinal persorption and tissue distribution of differently sized colloidal gold nanoparticles. J Pharm SCi 2001, 90:1927-1936.

34. Chithrani BD, Ghazani AA, Chan WCW: Determining the Size and Shape Dependence of Gold Nanoparticle Uptake into Mammalian Cells. Nano Letters 2006, 6:662-668

35. Li L, Zhu YJ: High chemical reactivity of silver nanoparticles toward hydrochloric acid. Journal of Colloid and Interface Science 2006, 303:415-418.

36. Elzey S, Grassian V: Agglomeration, isolation and dissolution of commercially manufactured silver nanoparticles in aqueous environments. Journal of Nanoparticle Research 2010, 12:1945-1958.

37. Sadauskas E, Wallin H, Stoltenberg M, Vogel U, Doering P, Larsen A, et al: Kupffer cells are central in the removal of nanoparticles from the organism. Particle and Fibre Toxicology 2007, 4:10.

38. Ham KN, Tange JD: Silver Deposition in rat glomerular basement membrane. Immunol Cell Biol 1972, 50:423-434.

doi:10.1186/1743-8977-8-18

Cite this article as: Loeschner et al:: Distribution of silver in rats

following 28 days of repeated oral exposure to silver nanoparticles or silver acetate. Particle and Fibre Toxicology 2011 8:18.

\section{Submit your next manuscript to BioMed Central} and take full advantage of:

- Convenient online submission

- Thorough peer review

- No space constraints or color figure charges

- Immediate publication on acceptance

- Inclusion in PubMed, CAS, Scopus and Google Scholar

- Research which is freely available for redistribution

Submit your manuscript at www.biomedcentral.com/submit 